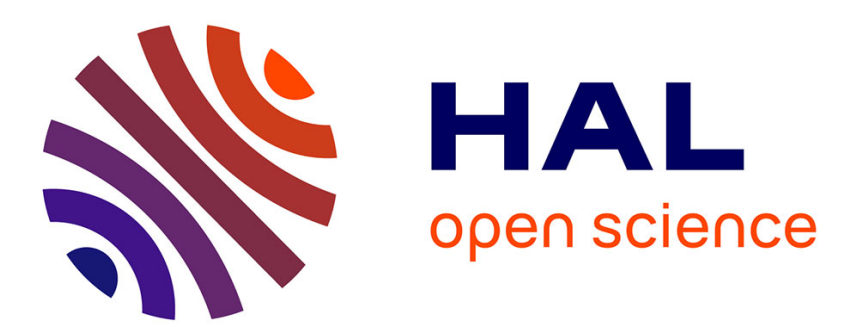

\title{
Effect of Bio-Based Monomers on the Scratch Resistance of Acrylate Photopolymerizable Coatings
}

\author{
Emeline Prandato, Sébastien Livi, Michel Melas, Justine Auclair, Vincent
}

Verney, Etienne Fleury, Françoise Mechin

\section{- To cite this version:}

Emeline Prandato, Sébastien Livi, Michel Melas, Justine Auclair, Vincent Verney, et al.. Effect of Bio-Based Monomers on the Scratch Resistance of Acrylate Photopolymerizable Coatings. Journal of Polymer Science Part B: Polymer Physics, 2015, 53 (5), pp.379-388. 10.1002/polb.23641 . hal01149573

\section{HAL Id: hal-01149573 \\ https://hal.science/hal-01149573}

Submitted on 13 Mar 2019

HAL is a multi-disciplinary open access archive for the deposit and dissemination of scientific research documents, whether they are published or not. The documents may come from teaching and research institutions in France or abroad, or from public or private research centers.
L'archive ouverte pluridisciplinaire HAL, est destinée au dépôt et à la diffusion de documents scientifiques de niveau recherche, publiés ou non, émanant des établissements d'enseignement et de recherche français ou étrangers, des laboratoires publics ou privés. 


\title{
Effect of bio-based monomers on the scratch resistance of acrylate photo- polymerizable coatings
}

\author{
Emeline Prandato ${ }^{1}$, Sébastien Livi $^{1}$, Michel Melas ${ }^{2}$, Justine Auclair ${ }^{3}$, Vincent Verney ${ }^{3}$, Etienne \\ Fleury ${ }^{1}$, Françoise Méchin ${ }^{1}$
}

1 Université de Lyon, CNRS, UMR 5223, INSA-Lyon, IMP@INSA, F-69621, Villeurbanne, France

2 Arkema, Centre de Recherche de l'Oise, Parc Technologique Alata, rue Jacques Taffanel, F-60550, Verneuil en Halatte, France

3 Institut de Chimie de Clermont-Ferrand, UMR 6296, Equipe Photochimie, Chimie 6, 24 avenue des Landais, BP 80026, F-63171, Aubière, France

Published in Journal of Polymer Science Polymer Physics vol. B53, 379-388 (2015)

\begin{abstract}
Photo-polymerizable clear coatings based on bio-sourced acrylates, dedicated to the protection of polycarbonate substrates, were studied. The bio-sourced compounds were not based on triglycerides but were smaller, industrially available molecules similar to classical petro-based monomers. Their polymerization kinetics was studied by photo-DSC and was shown to allow high acrylate conversions even at $25^{\circ} \mathrm{C}$. Closely related coatings enriched in alkyl segments, or in monoacrylates to decrease the cross-linking density, were compared. The material composition affects its nano-morphology deduced from X-ray diffraction. Although these changes in composition can slightly shift the mechanical relaxation, it remains wide and the elastic modulus remains high $\left(>10^{8} \mathrm{~Pa}\right)$ for all the tested materials. Micro-scratch experiments highlighted the efficiency of all the new coatings in terms of protection against scratches. Incorporating a monoacrylate, particularly isobornyl acrylate, can improve the scratch resistance especially in terms of critical load (up to $175 \%$ increase compared to a classical petro-based coating).
\end{abstract}

KEYWORDS: Photo-polymerization, micro-scratch, renewable, acrylate, photo-DSC, WAXD 


\section{INTRODUCTION}

Nowadays, many automotive components are made of thermoplastic in order for the vehicles to be lighter; headlights are for instance made of polycarbonate. However, an important drawback of this material is its low resistance to mechanical damage. Therefore the use of a coating is required, to protect the piece from impacts, abrasion or scratches. Protective coatings have to feature strong mechanical properties, such as a high elastic modulus, a good ability to recover their initial shape after deformation (i.e. a high elastic recovery) and a good resistance to indentation. The appearance of severe damage such as cracks is also expected to occur only for the highest stress as possible, since they can be the starting point of more severe damage.

In this prospect micro- or nano-scratch tests, which are used in the literature to assess the scratch resistance of coatings [1-3], are interesting. They consist in applying a constant or increasing load on an indenter in contact with the sample while it moves. The indented depth can be followed in real time and the elastic recovery can be calculated afterwards. The determination of the critical load, at which the first crack appears, also enables to compare the resistance of several materials. Different types of cracks can be observed, with or without chipping. Partial cone cracks are often obtained. More precisely when the test is carried out with an increasing load the cracks have the shape of a partial cone concave with respect to the direction of the scratch $[1,4]$. Indeed, the first crack appears when the tensile stresses (created at the rear of the indenter while scratching the sample with an increasing load) reach the ultimate tensile strength.

Protective coatings are most often polymer networks obtained by the polymerization of multifunctional compounds. Their properties are related to their composition, but also depend on the test conditions and on the temperature, since polymer materials display a viscoelastic behavior. Moreover during the buildup of a polymer network by radical (photo)-polymerization, numerous microgels are created and grow until they percolate to form a macrogel. From a morphological point of view, the resulting material is thus highly inhomogeneous at the micro or nanometer scale [5]; this can also have an impact on its macroscopic properties.

Protective coatings can be cured under UV-light. Photo-polymerization is indeed an interesting technology since it allows curing at high rate solvent-free mixtures deposited as low-thickness layers on a substrate. It is thus an economical and environmentally-friendly technology. However, 100\%solids protective coatings are generally composed of petro-based monomers. Faced with the depletion of fossil resources and in a sustainable development concern, the use of bio-based monomers could represent a "green" alternative.

In the literature, numerous recent works concerning bio-based UV-curable materials can be found [615]. However many of the related acrylate compounds derive from triglycerides extracted from vegetable oils. Dillman et al. [7], Huang et al. [9] and Rengasamy et al. [15] (meth)acrylated respectively castor oil, tung oil and a commercial epoxidized soybean oil. Pietschmann et al. also acrylated several vegetable oils such as rapeseed, linseed, soybean, calendula or castor oil [14]. Such molecules feature long alkyl chains, thus lead to networks with poor mechanical properties that are not suitable for a protective application. Yet there exist other commercial alternatives, such as short, multifunctional bio-based acrylate molecules similar to common petro-based monomers. The aim of the present work is to evaluate photo-polymerizable protective coatings for polycarbonate substrates, based on such compounds. The influence of the increase in alkyl segment content, or the decrease in the crosslinking density was also studied. This work includes the investigation of photo- 
polymerization kinetics using photocalorimetric measurements, the examination of the nanomorphology of the bio-based photo-cured materials by X-ray diffraction (XRD), as well as the evaluation of their thermomechanical properties by dynamic mechanical thermal analysis (DMTA) and their scratch resistance by micro-scratch tests.

\section{EXPERIMENTAL}

\section{Materials}

DiPEPHA (mixture of dipentaerythritol penta-acrylate and dipentaerythritol hexaacrylate, $15 \% \mathrm{BBC}$ ), PETA (pentaerythritol tetraacrylate, 10\% BBC), DDA (1,10-decanediol diacrylate, 60\% BBC), THFA (tetrahydrofurfuryl acrylate, 60\% BBC), LA (lauryl acrylate, $80 \% \mathrm{BBC}$ ) and IBOA (isobornyl acrylate, $75 \% \mathrm{BBC}$ ) are commercial partially bio-based acrylate oligomers and monomers provided by Arkema. TCDDA (tricyclodecane dimethanol diacrylate, SR833S) is a petro-based monomer also provided by Arkema. The structures of these compounds are detailed in Figure 1. The percentage of bio-based carbon (\% BBC) is calculated following Eq. (1):

$$
\% B B C=\frac{C_{\text {bio-based }}}{C_{\text {bio-based }}+C_{\text {petro-based }}} \times 100
$$

Irgacure 184 (1-hydroxycyclohexyl phenyl ketone) and Lucirin TPO-L (ethyl-2,4,6trimethylbenzoylphenylphosphinate) were used as photo-initiators; both were provided by BASF. 3,4,5-trichloropyridine (purity 99\%) was purchased from Aldrich. DMSO-d6 (deuterated dimethylsulfoxide) and tetramethylsilane (TMS) were purchased from Euriso-Top.

The polycarbonate substrates were injected Makrolon ${ }^{\circledR} \mathrm{AL} 2447$ plates with $\mathrm{Tg}=145^{\circ} \mathrm{C}$ and weight average molar mass $\mathrm{M}_{\mathrm{w}}=24 \mathrm{~kg} \cdot \mathrm{mol}^{-1}$ as determined by SEC with triple detection (LALS, refractometry and viscosimetry) [16].

\section{Preparation of the coatings}

Six different coatings were studied. Their compositions are summarized in Table 1. Bio 1 and Bio 3 differ by the nature of their oligomer, respectively DiPEPHA and PETA. Bio 2 was obtained by increasing the amount of DDA (+9.6\%) in Bio 1 while keeping the mass ratio between DiPEPHA and TCDDA constant. Bio 2 allows to study the influence of the enrichment in long alkyl chains on the properties of the material. Bio 11, Bio 12 and Bio 13 were obtained by substituting in Bio $14.8 \mathrm{wt} \%$ of the multicyclic petro-based monomer TCDDA by a variable monoacrylate monomer. These 3 coatings allow to study the influence of the decrease in the cross-linking density on the material properties.

The mean percentage of bio-based carbon in all the resulting coatings is $25-30 \%$. Note that a higher percentage could be reached if bio-based acrylic acid was used to provide the acrylic functionality to bio-based molecules, but it is not yet available at the industrial scale.

The raw materials were mixed with a Rayneri mixer at $700 \mathrm{rpm}$, first during 45 minutes (monomers alone), and for 15 more minutes after the addition of the photoinitiators. During this stage only a negligible increase in temperature $\left(<1^{\circ} \mathrm{C}\right)$ was observed. $15 \mu \mathrm{m}$ - and $150 \mu \mathrm{m}$-thick coatings deposited on polycarbonate (PC; Makrolon AL 2447) or glass panels were then prepared, with a motorized film applicator Elcometer K4340 equipped with a spiral bar coater. They were photo-polymerized through 3 passes under a Fusion F300S UV-lamp equipped with a conveyor belt. The mean total UV doses and irradiance peaks, measured with a Power Puck II (EIT), were respectively: UVA (320-290 nm): 3837

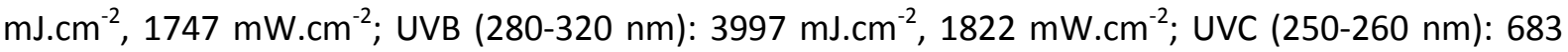


$\mathrm{mJ} . \mathrm{cm}^{-2}, 321 \mathrm{~mW} . \mathrm{cm}^{-2}$. The $150 \mu \mathrm{m}$-thick films prepared on glass panels were peeled off in order to get free-standing films for the DMTA analyses. The coatings on PC panels were especially designed for micro-scratch tests.

TABLE 1. Composition of the coatings (wt\%)

\begin{tabular}{cccccccccc}
\hline Coating & DiPEPHA & PETA & DDA & TCDDA & THFA & LA & IBOA & Irgacure 184 & Lucirin TPO-L \\
\hline Bio 1 & 23.2 & - & 36.5 & 36.5 & - & - & - & 1.5 & 2.3 \\
Bio 2 & 19.5 & - & 46.1 & 30.6 & - & - & - & 1.5 & 2.3 \\
Bio 3 & - & 23.2 & 36.5 & 36.5 & - & - & - & 1.5 & 2.3 \\
Bio 11 & 23.2 & - & 36.5 & 31.7 & 4.8 & - & - & 1.5 & 2.3 \\
Bio 12 & 23.2 & - & 36.5 & 31.7 & - & 4.8 & - & 1.5 & 2.3 \\
Bio 13 & 23.2 & - & 36.5 & 31.7 & - & - & 4.8 & 1.5 & 2.3 \\
\hline
\end{tabular}

Determination of the acrylate double bond conversion by Fourier Transform Infra-Red spectroscopy (FTIR)

The conversion degree of the cured samples was determined by FTIR, using an Attenuated Total Reflectance (ATR) device equipped with a diamond crystal. To calculate the acrylate double bond conversion, the area of the acrylate band at $810 \mathrm{~cm}^{-1}$ was used. It was normalized using the carbonyl band $\left(1720 \mathrm{~cm}^{-1}\right)$, which is constant throughout the polymerization, as a reference in order to avoid any bias related to incorrect contact between the sample and the crystal. A comparison of the ratio of these areas for both the cured and the uncured sample (without photo-initiators) allows to calculate the acrylate conversion degree after polymerization (Eq. 2):

$$
\text { Conversion }(\%)=100 \times\left(1-\frac{\left(\frac{A_{810 \mathrm{~cm}^{-1}}}{A_{1720 \mathrm{~cm}^{-1}}}\right)_{\text {cured }}}{\left(\frac{A_{810 \mathrm{~cm}^{-1}}}{A_{1720 \mathrm{~cm}^{-1}}}\right)_{\text {uncured }}}\right)
$$

The analyses were carried out with a NicoletTM iS10 spectrometer (ThermoScientific), equipped with a "Smart iTR" ATR unit. The spectra were acquired after 32 scans with a resolution $4 \mathrm{~cm}^{-1}$. The conversion could be determined for each side of the free standing films, but it could obviously be determined only on the upper side in contact with air during the polymerization of coatings on PC.

\section{Photocalorimetry studies}

\section{Preparation of the samples}

The photo-polymerization kinetics should not be too fast in order to be properly studied. Therefore, mixtures containing only one photo-initiator (Irgacure 184) were formulated, in a quantity such that the molar ratio I184/acrylate double bonds = 0.28\%; the compositions are summarized in Table 2 . 
TABLE 2. Composition of the mixtures studied by photo-DSC (wt\%); for each of them, the molar ratio between the photo-initiator and the acrylate double bonds equals $0.28 \%$

\begin{tabular}{ccccc}
\hline $\begin{array}{c}\text { Name of } \\
\text { the mixture }\end{array}$ & DiPEPHA & DDA & TCDDA & $\begin{array}{c}\text { Irga- } \\
\text { cure } \\
184\end{array}$ \\
\hline Bio 1" & 24.08 & 37.76 & 37.76 & 0.41 \\
"DDA" & - & 99.59 & - & 0.41 \\
"TCDDA" & - & - & 99.65 & 0.35 \\
"DiPEPHA" & 99.51 & - & - & 0.49 \\
\hline
\end{tabular}

The bio-based formulation Bio 1 was compared with each of its components alone. In this aim, the acrylate double bonds density $\left(d_{a c}\right)$ was previously determined for each monomer and oligomer by ${ }^{1} \mathrm{H}$ NMR, using 3,4,5-trichloro pyridine as internal standard [17]. A known mass of standard together with a known mass of acrylate compound were placed in the NMR tube. After the analysis, the integration of the proton signals related to the acrylate and to the standard enabled to calculate $d_{a c}$ (Eq. (3)):

$$
d_{a c}=\frac{I_{a c}}{I_{s}} \cdot \frac{2}{3} \cdot \frac{m_{s} \cdot p}{M_{s}} \cdot \frac{1}{m_{a c}}
$$

where $I_{a c}$ and $I_{e}$ are respectively the integrals of the acrylate and standard protons, $p$ and $M_{s}$ respectively the purity and the molar mass of the standard, $m_{a c}$ and $m_{s}$ respectively the mass of acrylate compound and of standard.

The spectra were acquired at $300 \mathrm{~K}$ in DMSO- $_{6}$ (+TMS), with a Bruker Avance III 400 US+ spectrometer $(400 \mathrm{MHz}), 8$ scans, $90 \mathrm{~s}$ relaxation delay and 128.103 points sampling.

\section{Experimental conditions}

A photo-calorimeter DSC 822e (Mettler Toledo) equipped with a LC6 (Hamamatsu) UV-lamp operating at $20 \%$ of its total power was used. The power received by the samples between 200 and $400 \mathrm{~nm}$ was $18.7 \mu \mathrm{W} . \mathrm{cm}^{-2}$ (measured with an Ocean Optics QE65000 spectro-photometer). The samples $(2-3 \mathrm{mg}$ ) were placed in $40 \mu \mathrm{L}$ aluminum capsules. The experiments were carried out at $25^{\circ} \mathrm{C}$; using such small samples the increase in temperature due to the reaction exothermy was negligible. Nitrogen was flushed during 5.5 min before the start of the irradiation, and then during the whole experiment, in order for the kinetics not to be disturbed by $\mathrm{O}_{2}$ inhibition. The samples were irradiated during $21.5 \mathrm{~min}$. At the end of each experiment, vitrification was reached, but the signal did not return to zero. This is due to the fact that the reference and sample pans do not absorb the infrared component of the radiation in the same way [18]. To avoid this effect, a second experiment was run under the same conditions immediately after the first one. The resulting signal was then subtracted from that obtained during the first run. By integrating the resulting heat flow, and considering it is proportional to the number of reacted acrylate double bonds, it is possible to calculate the acrylate conversion (Eq. (4)) 


$$
x(t)=\frac{1}{\Delta H_{100 \%}} \int_{0}^{t} H\left(t^{\prime}\right) d t^{\prime}
$$

where $\mathrm{x}(\mathrm{t})$ is the acrylate conversion (\%) at time $\mathrm{t}(\mathrm{s}) ; \mathrm{H}(\mathrm{t})$ is the heat flow versus time $(\mathrm{W}) ; \Delta \mathrm{H}_{100 \%}$ is the reaction enthalpy for $100 \%$ of the acrylate double bonds of the sample $(\mathrm{J})$, calculated following Eq. (5):

$$
\Delta \mathrm{H}_{100 \%}=\sum_{i} m_{i} \cdot n_{i} \cdot \Delta H_{C=\text { Cacrylate }}
$$

where $m_{i}$ is the mass $(\mathrm{g})$ of monomer or oligomer $\mathrm{i}$ in the sample, $n_{i}$ is the density of acrylate double bonds of the monomer or oligomer ( $\mathrm{mol} / \mathrm{g}), \Delta H_{C=C \text { acrylate }}$ is the reaction enthalpy for 1 mole acrylate double bonds (J/mol); we used $\Delta H_{c=c \text { acrylate }}=86 \mathrm{~kJ} / \mathrm{mol}[19]$.

Finally knowing the conversion vs. time relation, it is possible to calculate the polymerization rate $\left(R_{\text {polym }}\right.$ ) versus time (Eq. (6)):

$$
R_{\text {polym }}(t)=\frac{d x(t)}{d t}
$$

For each sample, 3 photo-DSC experiments leading to reproducible results were carried out. To compare the different studied samples, the maximal polymerization rate $\left(R_{\max }\right)$, its position in time and in acrylate conversion, and the final acrylate conversion $\left(x_{\max }\right)$ were simultaneously considered.

\section{X-Ray Diffraction (XRD)}

The diffractograms were collected with a Bruker D8 Advance X-ray diffractometer at the $\mathrm{H}$. Longchambon Diffractometry Center. A bent quartz monochromator was used to select the $\mathrm{Cu} K \alpha$ radiation $\left(\lambda_{r}=0.15406 \mathrm{~nm}\right)$. Experiments were run under operating conditions of $45 \mathrm{~mA}$ and $33 \mathrm{kV}$ in Bragg-Brentano geometry. The angle range $(2 \theta)$ was $4.5-50^{\circ}$. The diffractograms were analyzed and deconvoluted using the software Fityk. The apparent size of clusters of microgels was calculated using the Scherrer equation (Eq. 7, see Results \& Discussion section):

$$
D_{c}=\frac{k \lambda_{r}}{\beta_{d} \cos \theta}
$$

where $B_{d}$ is the width of the peak at the half-maximum height, and $\mathrm{k}$ is a constant depending on the direction of the lattice and the geometry of the clusters; here $k=1$ was used.

\section{Dynamic mechanical thermal analyses (DMTA)}

The DMTA were carried out with a TRITON apparatus, in tension mode, using the following experimental conditions: frequency: $1 \mathrm{~Hz}$; temperature ramp: $3^{\circ} \mathrm{C} / \mathrm{min}$ from $-90^{\circ} \mathrm{C}$ to $300^{\circ} \mathrm{C}$; deformation: $0.1 \%$, spacing between clamps: $2.5 \mathrm{~mm}$. $150 \mu \mathrm{m}$-thick free-standing films were analyzed (sample width: 5-10 mm), and at least 3 consistent analyses were carried out for each sample. 


\section{Micro-scratch tests}

Micro-scratch tests were carried out at $23^{\circ} \mathrm{C}$ and $50 \%$ relative humidity, with a CSM Micro-Scratch Tester equipped with a diamond Rockwell indentor featuring a $120^{\circ}$ angle and a $100 \mu \mathrm{m}$-radius sphere. The $4 \mathrm{~mm}$-long scratches were implemented on $15 \mu \mathrm{m}$-thick coatings deposited on PC, applying an increasing load from $0.03 \mathrm{~N}$ to $10 \mathrm{~N}$, at a speed $8 \mathrm{~mm} \cdot \mathrm{min}^{-1}$. The indented depth $\left(D_{i}\right)$ was followed in real-time during the test. A pre-scan and a post-scan, run with a constant load $0.03 \mathrm{~N}$, allowed to determine the residual depth $\left(D_{r}\right)$ and to calculate the elastic recovery $\left(R_{e}\right)$, following Eq. 8.

$$
R_{e}=\frac{\left(D_{i}-D_{r}\right)}{D_{i}} \cdot 100
$$

The elastic recovery expresses the ability of the sample to recover its initial shape. The load at which the first crack appears (critical load $L_{c}$ ) could be determined thanks to the observation of the scratch after the test with an optical microscope. For each sample, at least 5 micro-scratch tests were carried out. The results could not be statistically studied for each load between 0.03 and $10 \mathrm{~N}$, therefore the focus was put on the results $\left(D_{i}, D_{r}, R_{e}\right.$ and $\left.L_{c}\right)$ for two particular normal loads: $0.3 \mathrm{~N}$ and $1.5 \mathrm{~N}$. The errors are given for a probability of $95 \%$, and the reported values are averages of all the experimental data.

\section{RESULTS AND DISCUSSION}

The photo-polymerization of all the liquid mixtures (compositions in Table 1) led to clear tack-free coatings. In every case the mean acrylate conversion was about $95 \%$, i.e. a rather high value.

\section{Reaction kinetics estimated by photo-DSC}

Photo-DSC experiments were run to study the photo-polymerization kinetics of the mixture Bio 1' (same polymer matrix as Bio 1 with less photo-initiator). Indeed Bio 1 could not be directly studied because of its high photo-initiator content that speeds up the reaction and results in a less precise kinetic study. The evolution of the polymerization rate and of the acrylate conversion versus irradiation time is illustrated in Figure 2 for Bio $1^{\prime}$. As the experiments were run under $\mathrm{N}_{2}$ atmosphere, no induction period due to the oxygen inhibition of the polymerization could be noticed. As seen in Table 3, the maximal rate of polymerization was $2.1 \mathrm{~s}^{-1}$, and was reached after $8 \mathrm{~s}$ irradiation, when the acrylate conversion was $9.5 \%$. A high increase in the polymerization rate was initially observed, followed by a decrease until the polymerization stopped. This evolution is characteristic of the free-radical polymerization. The auto-acceleration, also named "gel effect", is due to the increase in the system viscosity as the polymerization proceeds. This decreases the mobility of the radicals located on the growing chains and thus slows the termination reaction. During this phase, the concentration of monomers decreases but they are still mobile. However, as the acrylate double bond conversion increases, the decrease in the mobility and concentration of monomers becomes important and the polymerization rate starts to decrease as well, leading to auto-deceleration. The polymerization finally stops because of vitrification, or when all the acrylate double bonds are consumed. 
The final conversion for the mixture Bio $1^{\prime}$ was $68.4 \%$. So, even at $25^{\circ} \mathrm{C}$, the conversion of the acrylate double bonds reaches a high value. The high conversion ( $95 \%)$ noticed after 3 passes under the UV-lamp where the temperature can reach $90^{\circ} \mathrm{C}$ is thus not surprising.

To confirm the reactivity of the mixture Bio $1^{\prime}$, the photo-polymerization kinetics of each acrylate compound used to formulate it was then studied separately (compositions given in Table 2).

For all samples, no induction period was ever noticed, and the characteristic auto-acceleration and auto-deceleration phenomena were always observed. The results are summarized in Table 3. It appears that the photo-polymerization kinetics of the oligomer DiPEPHA is much lower than that of the diacrylate monomers TCDDA and DDA. Indeed, the maximal rate is reached for a much longer irradiation time and a much lower conversion in the case of the oligomer.

TABLE 3. Results of the photo-DSC experiments for Bio 1' and for the corresponding pure acrylate compounds; $R_{\max }$ : maximal polymerization rate; $x_{\max }$ : maximal acrylate conversion. For each sample, the indicated values are averages over 3 consistent experiments

\begin{tabular}{ccccc}
\hline & \multicolumn{3}{c}{ Position of $\mathrm{R}_{\max }$} & \\
\cline { 2 - 4 } Sample & $\begin{array}{c}\text { Irradiation } \\
\text { time }[\mathrm{s}]\end{array}$ & $\begin{array}{c}\text { Acrylate } \\
\text { conversion } \\
{[\%]}\end{array}$ & $\begin{array}{c}\mathrm{R}_{\max } \\
{\left[\mathrm{s}^{-1}\right]}\end{array}$ & $\begin{array}{c}\mathrm{X}_{\max } \\
{[\%]}\end{array}$ \\
\hline Bio 1' & 8 & 9.5 & 2.1 & 68.4 \\
DDA & 15 & 28.0 & 2.8 & 87.9 \\
TCDDA & 10 & 14.0 & 2.9 & 61.6 \\
DiPEPHA & 48 & 5.7 & 0.1 & 35.5 \\
\hline
\end{tabular}

For this oligomer DiPEPHA, the final acrylate conversion is also quite low ( $\sim 35.5 \%)$. These features are due to its high viscosity ( $10 \mathrm{~Pa} . \mathrm{s}$ at $\left.25^{\circ} \mathrm{C}\right)$ [20] and high functionality, which both contribute to hamper the diffusion of the reactive species. On the contrary, the other two diacrylates have a lower viscosity (130 mPa.s for TCDDA and 10 Pa.s for DDA at $25^{\circ} \mathrm{C}$, data given by Arkema). Their photopolymerization is thus faster, and their final conversion higher. In addition, for TCDDA the maximal photo-polymerization rate is reached at lower irradiation time and acrylate conversion than for DDA. What is more, its final conversion is also lower than for DDA (61.6\% versus $87.9 \%$ ). This can be attributed to the rigid structure of TCDDA, due to its 3 joined cycles. With this monomer the growing polymer network is rigid even at low acrylate conversion, and vitrification is quickly reached. To confirm this, DMTA was carried out for $99 \%$-cured mixtures containing only photo-initiators and TCDDA or DDA, in order to determine the maximal temperature of the mechanical relaxation of "totally" cured monomers. For TCCDA, this value was about $252^{\circ} \mathrm{C}$ whereas it was approximately $107^{\circ} \mathrm{C}$ for DDA. These results confirm that vitrification is reached at a lower conversion degree for TCDDA than for DDA, and are thus in agreement with the respective final conversions observed for the two samples.

\section{Nanostructure of the coatings}

As explained in the Introduction, the nanostructure of the studied coatings, obtained by the photopolymerization of multifunctional acrylate compounds, is supposed to be very inhomogeneous with agglomerated highly crosslinked microgels linked by a less crosslinked matrix. However, the chemical 
nature of the different domains must be very similar, and indeed traditional characterization methods such as Atomic Force Microscopy, AFM (regular and Peak Force tapping modes), or Transmission Electron Microscopy, TEM, performed on both neat and variously stained samples (using $\mathrm{RuO}_{4}$ or phosphotungstic acid at $\mathrm{pH}=4.0$ or 7.2 ) did not allow the detection of distinctly separated nanophases in our materials. Quite recently, Barszczewska-Rybarek [21] analyzed the nano-morphology of a series of previously powdered polyacrylate materials based on 3 precursors with quite different chemical structures by X-ray diffraction. Diffractograms with 3 main broad peaks were obtained; these peaks were assumed to be associated with 3 representative sizes of microgel clusters. In other words, the $D_{c}$ value determined from the Scherrer equation (Eq. 7) was considered as a measure of the size of the various heterogeneities (agglomerated microgels) present in the polyacrylate network. It could objected that Scherrer's equation is usually considered applicable only to crystalline domains; however such amorphous microgel structures obtained from photopolymerization were already shown to display a definite local order [22]. This spatial organization was also experimentally observed by Rybarek on dimethacrylate networks [23]; WAXS and its classical equations were also used to study interchain spacing in amorphous homopolymers and blends [24]. In our case, a local organization is definitely detected by $X$ rays, and all these arguments are finally in favor of similar size calculations using Scherrer's equation. Inspired by these works, we therefore attempted to analyze the nanostructure of the present photo-cured materials $(150 \mu \mathrm{m}$ thick free films) by XRD in the same way. The diffractograms (Figure 3) revealed several large "peaks" typical of amorphous materials. The results of the deconvolution of these peaks (angle and corresponding $D_{c}$ value) are summarized in Table 4 . In this table, the parameter $D_{\text {tot }}$ (sum of all individual $D_{c i}$ for a given network) that is considered as an indicator of the network heterogeneity in Barszczewska-Rybarek's work, is also given.

TABLE 4. Analysis of the X-ray diffractograms of the bio-based materials

\begin{tabular}{ccccccc}
\hline & & Bio 1 & Bio 3 & Bio 11 & Bio 12 & Bio 13 \\
\hline $\begin{array}{c}\text { "Peak" } \\
\text { n¹ }\end{array}$ & Angle 2 $\left(^{\circ}\right)$ & 5.0 & 6.8 & 6.9 & 5.6 & 5.8 \\
\hline $\begin{array}{c}\text { "Peak" } \\
\text { n² }\end{array}$ & $D_{c}(\mathrm{~nm})$ & 1.8 & 2.8 & 4.0 & 2.1 & 2.3 \\
\hline $\begin{array}{c}\text { "Peak" } \\
\mathrm{n}^{\circ} 3\end{array}$ & $D_{c}(\mathrm{~nm})$ & 1.2 & 0.8 & 1.2 & 1.2 & 1.2 \\
\hline $\begin{array}{c}\text { "Peak" } \\
\mathrm{n}^{\circ} 4\end{array}$ & $D_{c}(\mathrm{~nm})$ & 18.7 & 18.1 & 19.1 & 19.0 & 18.7 \\
\hline & $D_{c}(\mathrm{~nm})$ & 1.2 & 1.3 & 1.3 & 1.2 & 1.3 \\
\hline & $D_{\text {tot }}(\mathrm{nm})$ & 4.2 & 5.5 & 6.5 & 4.5 & 4.8
\end{tabular}

For all the samples except Bio 3, three "peaks" were detected and used for analysis, which led to two different apparent sizes of microgel clusters $\left(D_{c}\right)$ which is the primary cause of the structural heterogeneity in networks [25]. The fact that two "peaks" can lead to a similar value of $D_{c}$ evidences the great inhomogeneity of the samples. All these samples display rather similar results, except for "peak" $n^{\circ} 1$, whose position in terms of angle $2 \theta$ and the corresponding calculated value of $D_{c}$ varies. This suggests that the size of the biggest clusters depends on the composition of the material. 
According to the literature, the $D$ values are similar to those observed for dimethacrylate networks [23]. In fact, Rybarek studied the influence of different copolymers on the structural heterogeneity parameter and attributed the increase in this parameter to the strength of molecular interactions in the cured system. Compared to another study, this latter size is always much lower than the highest values depicted in ref [21] where $D_{\text {tot }}$ often reaches 11-14 $\mathrm{nm}$. In this latter work, large clusters are said to be promoted both by the initial presence of strong hydrogen bonds between some monomer molecules, and by $\pi-\pi$ stacking interactions between phenyl rings. Therefore the difference might be due to several factors: i) all the networks studied here were highly converted ( 95\%) contrary to the quoted literature; ii) the chemical structures of the various precursors used in the present work were maybe more alike than those used by Barszczewska-Rybarek, inasmuch as iii) they were not able to generate many hydrogen bonds (no urethane group); and finally iv) no aromatic monomer was used.

Sample Bio 3, which is the only one containing PETA, is slightly different from the others because the central peak could be deconvoluted into two peaks, leading to similar apparent sizes of clusters of microgels. Once again this tends to confirm that the composition of the material has some influence on its nano-structure.

In conclusion, the size of heterogeneities and the number of hydrogen bonds will have a significant influence on the mechanical properties of the final material, such as the impact strength.

\section{Thermomechanical properties of the materials}

A protective coating is expected to display a high elastic modulus and a large mechanical relaxation in order to prevent the properties of the coating from varying abruptly with a change in temperature. This is of particular importance when the protected piece has a broad range of operating temperature (outdoor applications).

Here all the studied materials display a rather similar high elastic modulus, lying between 4 and $6.10^{8}$ $\mathrm{Pa}$ at the rubbery plateau; its variation during the mechanical relaxation is lower than one decade (for all the samples E'glassy $=2$ to $3.10^{9} \mathrm{~Pa}$ ). A finer comparison of the samples' moduli appears somewhat risky because of the insufficient sensitivity of the used rheometer and of the experimental difficulty in analyzing these extremely brittle materials.

For polyacrylate networks, the crosslinking density and the elastic modulus at the rubbery plateau are related in a complex way [26]. Nevertheless, the substitution of $5 \mathrm{wt} \%$ diacrylate by a monoacrylate in the coating Bio 1 (Bio 11, Bio 12 and Bio 13) does not seem to be sufficient to induce a noticeable decrease in the elastic modulus. The enrichment in alkyl segments (Bio 2, compared to Bio 11) has no influence on the elastic modulus of the material.

As can be seen in Figure 4, for no sample can a secondary mechanical relaxation be noticed, and the principal relaxation is always broad which highlights the presence of many heterogeneities at the nanometer scale in the network and confirms the X-ray diffraction results $[27,28]$. The characteristics of the mechanical relaxations are summarized in Table 5. 
TABLE 5. Characteristics of the mechanical relaxation of the bio-based photo-cured materials, determined by DMTA at $1 \mathrm{~Hz}$

\begin{tabular}{ccc}
\hline Coating & $\begin{array}{c}\text { Temperature } \\
\text { at the } \\
\text { maximum }\left({ }^{\circ} \mathrm{C}\right)\end{array}$ & $\begin{array}{c}\text { Width at } \\
\text { half maximal } \\
\text { height }\left({ }^{\circ} \mathbf{C}\right)\end{array}$ \\
\hline Bio 1 & 137 & 115 \\
Bio 2 & 117 & 106 \\
Bio 3 & 135 & 103 \\
Bio 11 & 127 & 107 \\
Bio 12 & 126 & 101 \\
Bio 13 & 147 & 117 \\
\hline
\end{tabular}

At room temperature, all the studied materials are in the glassy state. The variation of the width at half maximal height from one to another sample is negligible. The substitution of DiPEPHA by PETA in Bio 1 (leading to coating Bio 3 ) does not modify the position of the mechanical relaxation. However, a $20^{\circ} \mathrm{C}$ gap between the maximum of these relaxations is observed for Bio 1 and Bio 2. The enrichment in alkyl chains (Bio 2) shifts the mechanical relaxation toward lower temperatures. This is attributed to the $\mathrm{C} 10$ chain of DDA, which can favor longer relaxation times and consequently, following the equivalence principle between time and temperature, can favor the shift or the enlargement of the mechanical relaxation toward lower temperatures. Although the incorporation of a monoacrylate should decrease the crosslinking density of the polymer network, the observations differ following which monoacrylate is considered. The incorporation of IBOA (Bio 13) indeed shifts the maximum of the mechanical relaxation toward higher temperatures. This is due to its tricyclic hard structure: in order to provide it mobility, it is necessary to bring a high amount of energy. This effect prevails on the loosening of the polymer network through the incorporation of a monoacrylate. On the contrary, the maximum of the mechanical relaxation is logically shifted toward lower temperatures with THFA or $L A$, because the polymer network is loosened and this effect is not counterbalanced by the rigidity of the added monomer.

As a conclusion, every studied sample features thermomechanical properties in agreement with our expectations for a protective application. Other tests are thus necessary to reveal some difference between them.

\section{Scratch resistance of the coatings}

In Figure 4, the temperature used for the microscratch experiments $\left(23^{\circ} \mathrm{C}\right)$ lies before or at the very beginning of the mechanical relaxation for all the samples. Therefore they should all be in a rather similar viscoelastic state. The results of the micro-scratch experiments for the bio-based coatings as well as for the uncoated PC substrate are presented in Figure 5. The coatings do not prevent the penetration of the indenter (Fig. 5a), but they all improve the elastic recovery (Fig $\mathbf{5 c}$ ) and thus notably limit the residual depth of the scratch (Fig. 5b). Yet, this residual depth is expected to be as low as possible, since the deeper it is, the more visible the scratch is. As for the critical load (Fig. 5d), the improvement is remarkable with respect to a classical petro-based formulation [29] that showed a $1.9 \mathrm{~N}$ critical load under the same test conditions, i.e. an increase ranging from 60\% for Bio 12 to $\sim 175 \%$ for Bio 13 . All the studied coatings are thus effective in terms of protection against scratches. 
The replacement of the oligomer DiPEPHA in Bio 1 by PETA (coating Bio 3) slightly increases the elastic recovery, while the effect on the indented depth is negligible. Taking into account the experimental uncertainty, no change in the critical load can be noticed.

Comparing coatings Bio 1 and Bio 2, it appears that the enrichment in alkyl segments does not either influence the scratch resistance of the coatings (see Figure 5).

In coating Bio 1 , the substitution of 5\% TCDDA by a monoacrylate should lead to a decrease in the crosslinking density. In fact a slight increase in the elastic recovery can be observed as a result of this substitution (Figure 5c, Bio 11, Bio 12, Bio 13). Its influence on the critical load once again depends on the monoacrylate nature and is particularly noticeable in the case of IBOA that tends to increase Lc (Bio 13). In order to explain this, the acrylate double bond density of each mixture was first calculated. Values of $7.2 .10^{-3}$ mol.g $\mathrm{g}^{-1}, 7.1 .10^{-3} \mathrm{~mol} . \mathrm{g}^{-1}$ and $7.1 .10^{-3} \mathrm{~mol}^{-\mathrm{g}^{-1}}$ were found respectively for Bio 11, Bio 12 and Bio 13. As all the coatings have a similar conversion degree (95\%), it can be assumed that their crosslinking density is similar. The observed differences can thus be ascribed to the chemical structure of the monoacrylate. As the critical load tends to be higher for Bio 13, IBOA must either restrain the increase in stresses in the polymer network, and/or shift the ductile-brittle transition toward higher temperature, certainly due to its bulky structure. On the contrary, LA must increase the stresses in the material since the critical load tends to be lower for Bio 12. Finally THFA has virtually no effect on the critical load.

Since cracks represent severe damage, the critical load is a very important parameter; it is obviously expected to have a high value. Taking this into account, Bio13 is a rather interesting coating, since it combines satisfying elastic recovery and critical load, as well as a slightly lower residual depth.

Scratches and cracks were finally observed with an optical microscope. As shown in Figure 6, no crack was created along the scratch in the case of the uncoated PC. For the other samples, all the cracks have the same shape; partial cone cracks can be recognized [1]. As the shape of the cracks is related to the spatial organization of the stress fields created in the material during the scratch $[30,31]$, these fields can be assumed to be spatially organized in a rather same way in all the tested bio-based coatings.

\section{CONCLUSIONS}

Photo-polymerized clear tack-free coatings were obtained using bio-sourced monomers similar to classical petro-based products. The kinetics of the photo-polymerization reaction was shown to be quite comparable to that of usual systems, and is therefore fully compatible with industrial curing processes.

As usual microscopic techniques (AFM and TEM) did not allow to reveal possibly separated nanophases, the nano-morphology of the materials was investigated by XRD. Clusters of microgels of different apparent sizes were assumed to be present. These sizes were all very small $(<5 \mathrm{~nm})$, suggesting that the presence of the clusters could probably not be evidenced by SAXS either. Nevertheless, the results indicated an influence of the composition on these sizes.

All the studied samples feature a high elastic modulus and a wide mechanical relaxation, which is in agreement with our expectations for a material dedicated to a protective use. What is more, the 15 $\mu \mathrm{m}$-thick coatings all efficiently protect the polycarbonate substrate from scratches. 
The enrichment of the material in alkyl segments shifts the mechanical relaxation toward lower temperatures, and has no influence on the scratch resistance.

The decrease in the cross-linking density through the incorporation of a monoacrylate monomer slightly shifts the mechanical relaxation toward higher (IBOA) or lower (THFA, LA) temperatures. The micro-scratch experiments showed that this change in composition generally tends to increase the elastic recovery, but that the effect on the critical load depends on the monoacrylate. The incorporation of $5 \mathrm{wt} \%$ IBOA is particularly attractive since it allows a slightly higher elastic recovery along with a distinctly higher critical load.

\section{ACKNOWLEDGEMENTS}

This work was funded by the French FUI (Fond Unique Interministériel), under the aegis of Plastipolis and Mov'eo Competitivity Poles, as the Collaborative Project "3V" (Vernis Verts à très longue durée de Vie). We gratefully acknowledge all the partners from the $3 \mathrm{~V}$ Project for fruitful discussions. We also thank Ruben Vera from the Centre de Diffractométrie H. Longchambon for the XRD experiments, and the NMR Polymer Center of the "Institut de Chimie de Lyon" (FR3023), for assistance and access to the NMR facilities. Finally Pierre Alcouffe (UMR5223) is gratefully acknowledged for his numerous attempts to visualize the nanophases by AFM and TEM.

\section{REFERENCES AND NOTES}

[1]. J. Caro, N. Cuadrado, I. González, D. Casellas, J.M. Prado, A. Vilajoana, P. Artús, S. Peris, A. Carrilero, J.C. Dürsteler, Surf. Coat. Technol., 2011, 205, 5040-5052.

[2]. V. Jardret, B.N. Lucas, W. Oliver, A.C. Ramamurthy, J. Coat. Tech., 2000, 72, 79-88.

[3]. S.M. Noh, J.W. Lee, J.H. Nam, K.H. Byun, J.M. Park, H.W. Jung, Prog. Org. Coat., 2012, 74, 357269.

[4]. V. Jardret, P. Morel, Prog. Org. Coat., 2003, 48, 322-331.

[5]. E. Andrzejewska, Prog. Polym. Sci., 2001, 26, 605-665.

[6]. Z. Chen, J.F. Wu, S. Fernando, K. Jagodzinski, Prog. Org. Coat., 2011, 71, 98-109.

[7]. B.F. Dillman, N.Y. Kang, J.L.P. Jessop, Polymer, 2013, 54, 1768-1774.

[8]. L. Fertier, H. Koleilat, M. Stemmlen, O. Giani, C. Joly-Duhamel, V. Lapinte, J.-J. Robin, Prog. Polym. Sci. 2013, 38, 932-962.

[9]. Y. Huang, L. Pang, H. Wang, R. Zhong, Z. Zheng, J. Yang, Prog. Org. Coat., 2013, 76, 654-661.

[10]. A. Palanysamy, B.S. Rao, Prog. Org. Coat., 2007, 60, 161-169.

[11]. K.I. Patel, R.J. Parmar, J.S. Parmar, J. Appl. Polym. Sci., 2008, 107, 71-81.

[12]. B.S. Rao, A. Palanysamy, Prog. Org. Coat., 2008, 63, 416-423.

[13]. B.S. Rao, A. Palanysamy, Prog. Org. Coat., 2010, 67, 6-11.

[14]. N. Pietschmann, K. Stengel, Farbe und Lack, 2004, 110, 29-33.

[15]. S. Rengasamy, V. Mannari, Prog. Org. Coat., 2013, 76, 78-85. 
[16]. S. Laurent, Développement et études de l'influence des procédés d'application et de réticulation de vernis acrylates photo-polymérisables (à 100\% d'extrait sec), PhD Thesis, INSA-Lyon, Villeurbanne, France, January 2014.

[17]. T. Rundlöf, M. Mathiasson, S. Bekiroglu, B. Hakkarainen, T. Bowden, T. Arvidsson, J. Pharma. Biomed. Anal., 2010, 52, 645-651.

[18]. T. F. Scott, W. D. Cook, J. S. Forsythe, Polymer, 2002, 43, 5839-5845.

[19]. E. Andrzejewska, M. Andrzejewski, J. Polym. Sci, Part A: Polym. Chem., 1998, 36, 665-673.

[20]. D.S. Esen, F. Karasu, N. Arsu, Prog. Org. Coat., 2011, 70, 102-107.

[21]. I.M. Barszczewska-Rybarek, Macromol. Chem. Phys. 2013, 214, 1019-1026.

[22]. L. Rey, J. Duchet, J. Galy, H. Sautereau, D. Vouagner, L. Carrion, Polymer, 2002, 43, 4375-4384.

[23]. I. Barszczewska-Rybarek, Dent. Mater., 2009, 25, 1082-1089.

[24]. A.F. Halasa, G.D. Wathen, W.L. Hsu, B.A. Matrana, J.M. Massie, J. Appl. Polym. Sci., 1991, 43, 183-190.

[25]. K.S. Anseth, K.J. Anderson, C.N. Bowman, Macromol. Chem. Phys., 1996, 197, 833.

[26]. A.R. Kannurpatti, J.W. Anseth, C.N. Bowman, Polymer, 1998, 39, 2507-2513.

[27]. G.P. Simon, P.E.M. Allen, D.R.G. Williams, Polymer, 1991, 32, 2577-2587.

[28]. T.W. Wilson, J. Appl. Polym. Sci. 1990, 40, 1195-1208.

[29]. E. Prandato, M. Melas, E. Fleury, F. Méchin, Prog. Org. Coat., in press (DOI: 10.1016/j.porgcoat.2014.06.012).

[30]. F.C. Frank, F.R.S. Lawn, B.R. Lawn, Proc. R. Soc. London Ser. A, 1967, 299, 291-306.

[31]. B.R. Lawn, Proc. R. Soc. London Ser. A, 1967, 299, 307-316. 
<smiles>C=C[CH+]=CC(=O)OCC(COCC(COCC(COC(=O)C=C)(COC(=O)C=C)COC(=O)C=C)(COC(=O)C=C)COC(=O)C=C)(COC(=O)C=C)COC(=O)C=C</smiles>

a<smiles>C=CC(=O)OCCCCCCCCCCOC(=O)C=C</smiles><smiles>C=CC(=O)OCC(COC(=O)C=C)(COC(=O)C=C)COC(=O)C=C</smiles><smiles>C=CC(=O)OC1CC2CC(C)(C)C1(C)C2</smiles>

e<smiles>C=CC(=O)OCCCCCCCCCCCC</smiles>

f

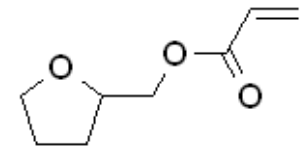

g

Figure 1 : Structure of the oligomers and monomers: DiPEPHA (a), TCDDA (b), DDA (c), PETA (d), IBOA (e), LA (f), THFA (g) 


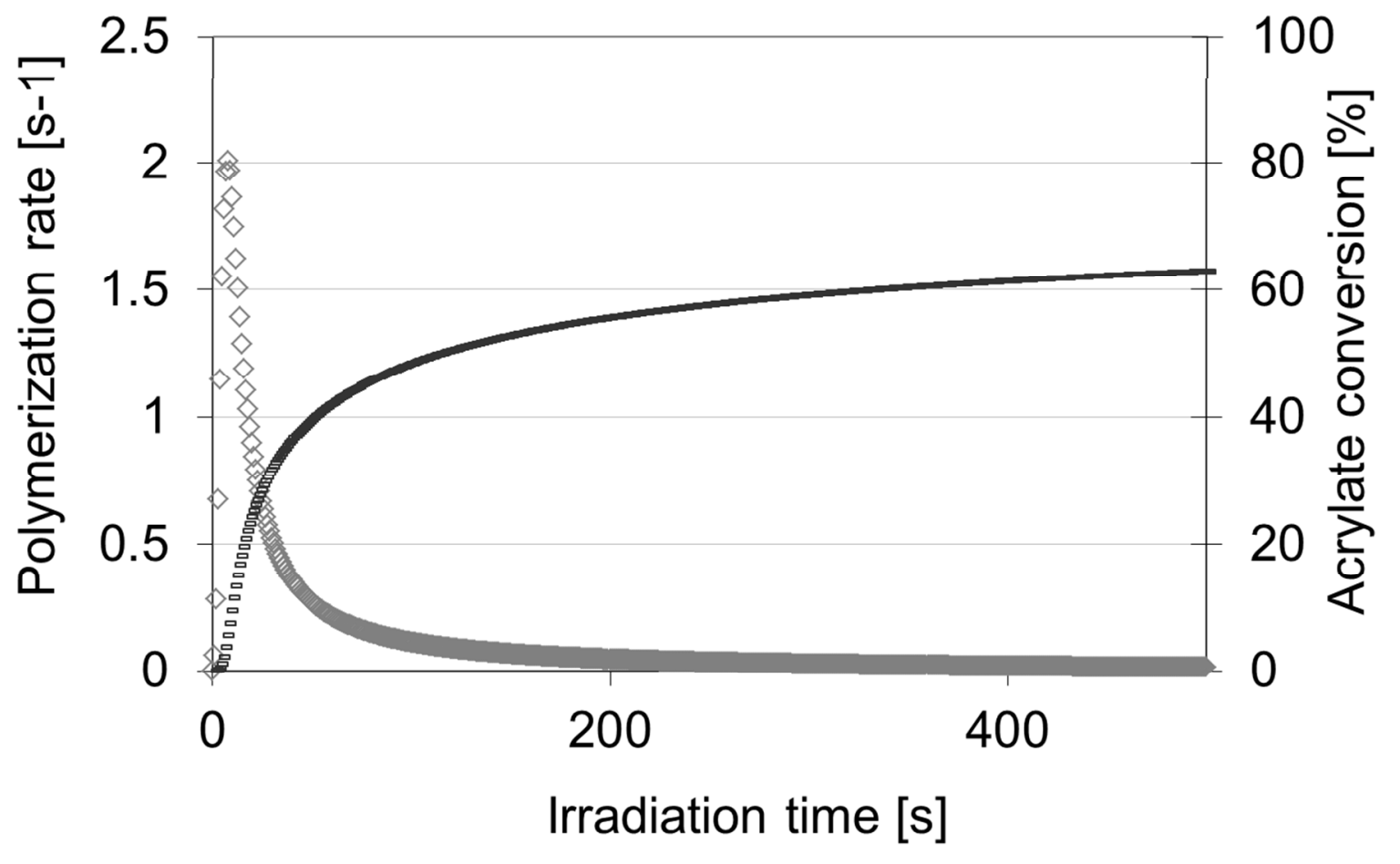

Polymerization rate -Acrylate conversion

Figure 2 : Kinetics of photo-polymerization of the mixture Bio $1^{\prime}$, studied by photo-DSC at $25^{\circ} \mathrm{C}$ 

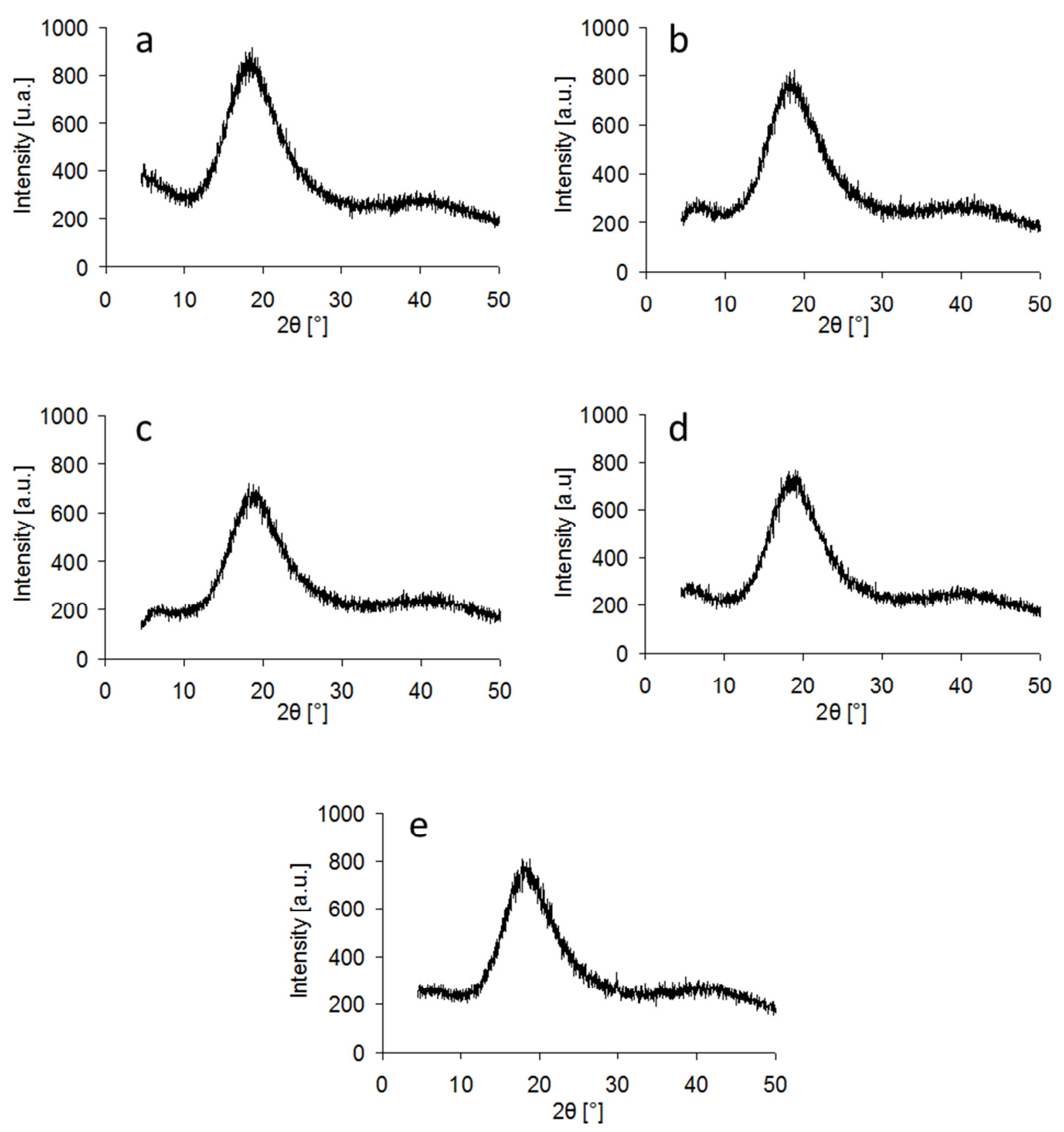

Figure 3 : Wide-angle X-ray diffraction spectra of the materials Bio 1 (a), Bio 3 (b), Bio 11 (c), Bio 12 (d) and Bio 13 (e) 


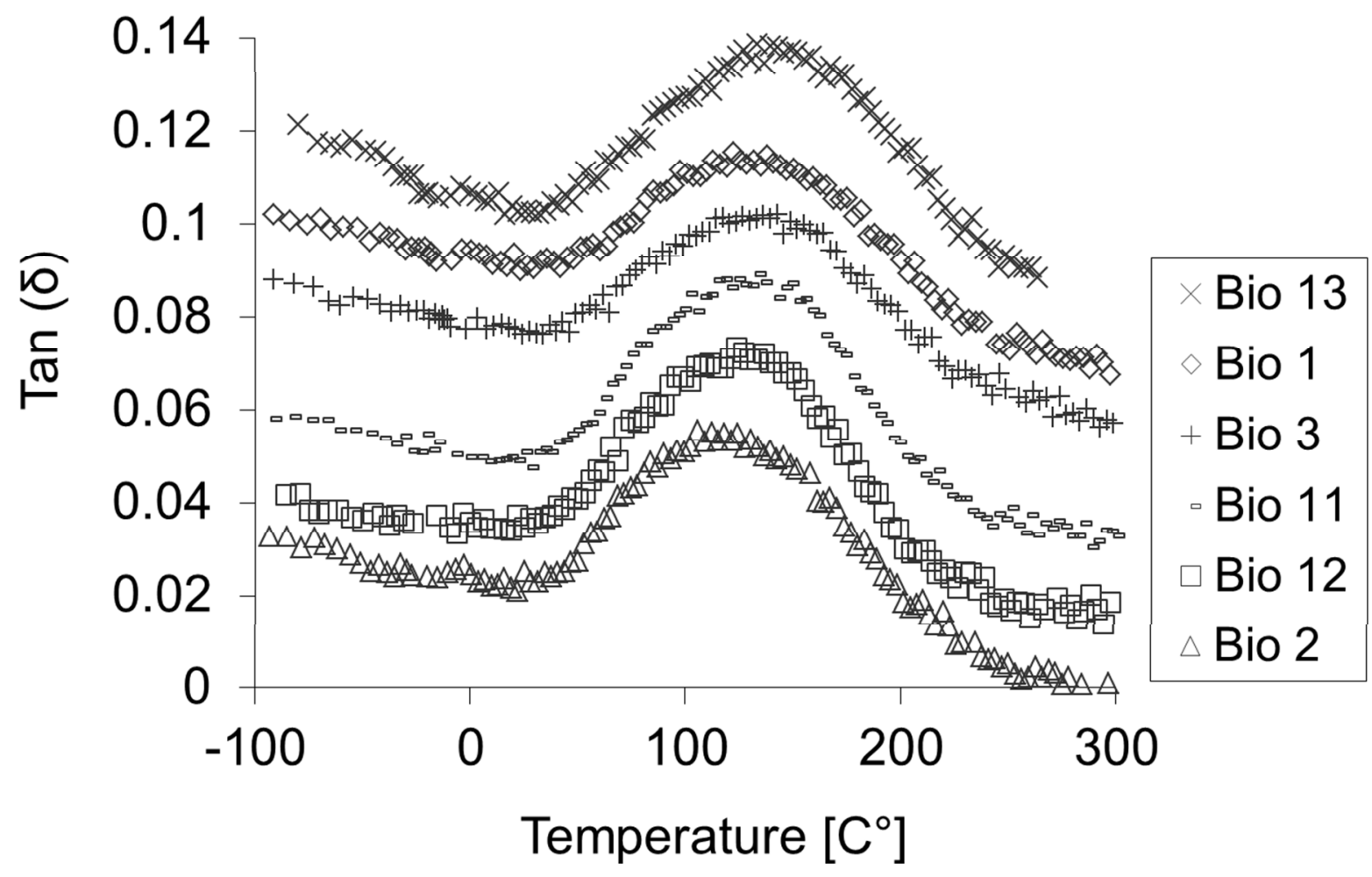

Figure 4 : Evolution of the loss factor during DMTA at $1 \mathrm{~Hz}$ for the studied bio-based polyacrylate materials; the curves where vertically shifted in order to make the comparison easier, the values should therefore not be taken into account 


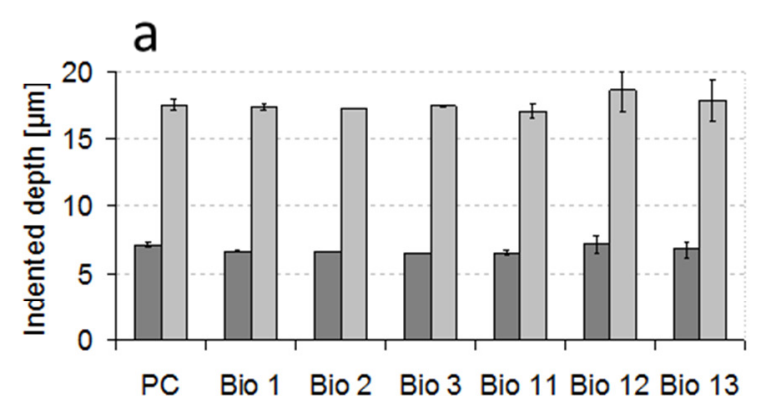

$\square$ Normal load: $0,5 \mathrm{~N} \square$ Normal load: $1,3 \mathrm{~N}$

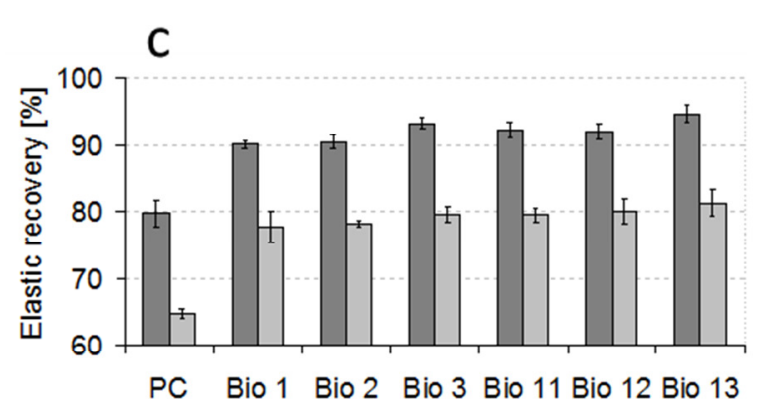

$\square$ Normal load: $0,5 \mathrm{~N} \square$ Normal load: $1,3 \mathrm{~N}$
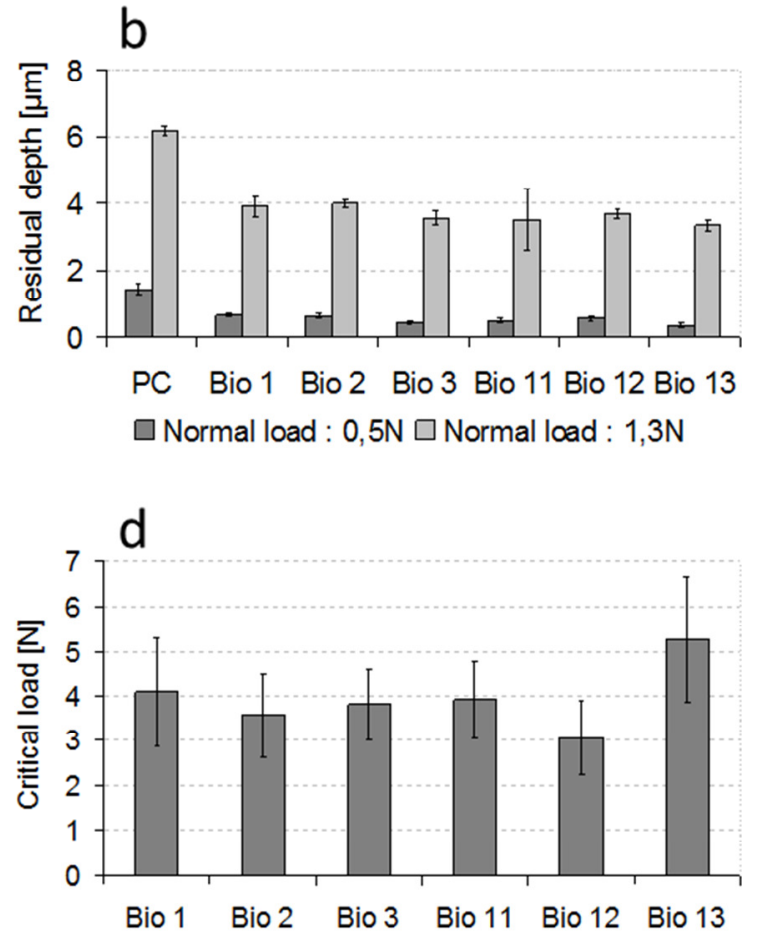

Figure 5 : Results of the micro-scratch tests for the bio-based $15 \mu \mathrm{m}$-thick coatings deposited on PC: indented depth (a), residual depth (b), elastic recovery (c), critical load (d) 


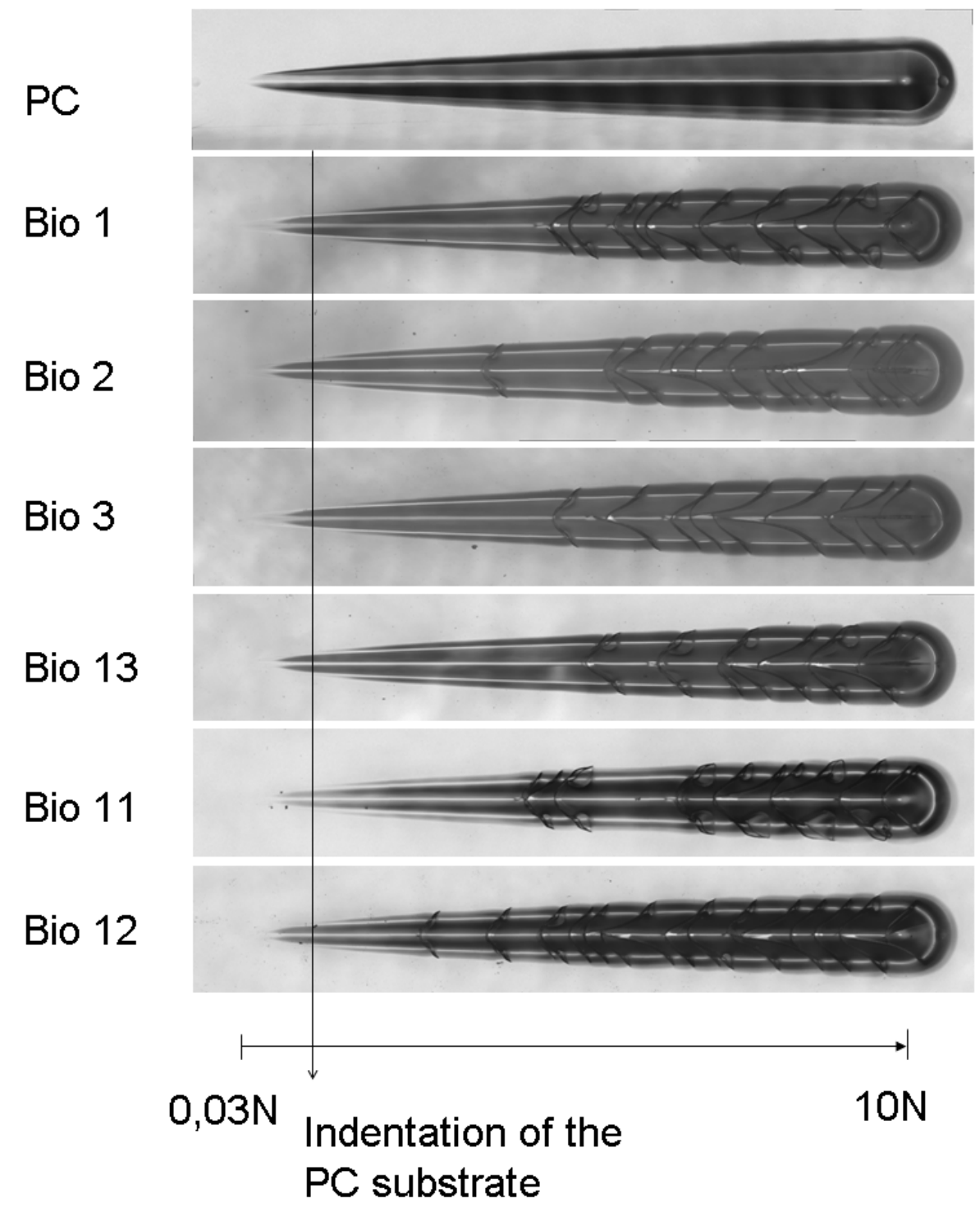

Figure 6 : Observation with an optical microscope of the scratches on the uncoated PC and on the bio-based $15 \mu \mathrm{m}$-thick coatings deposited on PC 